Fernandes et al.

Volume 3 Issue 2, pp.01-12

Date of Publication: 15th November 2017

DOI-https://dx.doi.org/10.20319/mijst.2017.32.112

\title{
DYNAMIC NUMERICAL SIMULATION OF DIFFERENT DRILL BIT DIAMETER ON THE POLYURETHANE FOAMS DRILLING
}

\author{
Maria G Fernandes \\ PhD Student, INEGI, Faculty of Engineering, University of Porto, Porto, Portugal, \\ mgfernandes@inegi.up.pt \\ Elza M M Fonseca \\ LAETA, INEGI, Polytechnic Institute of Bragança, Portugal \\ efonseca@ipb.pt \\ Tiago A S Teixeira \\ MSc Student, Polytechnic Institute of Bragança, Bragança, Portugal \\ tiago.tast22@gmail.com \\ Renato N Jorge \\ INEGI, Faculty of Engineering, University of Porto, Porto, Portugal \\ rnatal@fe.up.pt
}

\begin{abstract}
Drilling is one of the most common processes involved in different cutting operations and may affect the mechanical properties of the workpiece by creating residual stresses around the opened hole and highly stressed on the newly formed surface. Nevertheless, when it comes to the living tissues, drilling assumes more attention to guarantee a non-invasive procedure. Drilling of bone is common in orthopaedic surgical process, to produce a hole to screw insertion to fix the fractured members for immobilization, or even in dental implant interventions. This work describes a conventional drilling process performed on solid rigid polyurethane foams blocks with similar mechanical properties to the human bone. A dynamic and numerical study was conducted to evaluate the use of different drill diameters (4, 5 and 6mm) on the stresses generated during the process. Different simulations using an explicit dynamic program were performed to assess the level of stresses and the damage effect on the polyurethane foam


structure. This program is based on the finite element method and incorporates the dynamic characteristics involved in the drilling process. The main objective of this study is to verify the combination between some drill parameters, that reduce the mechanical damage produced by high stress level during bone drilling. The results permit to assess the influence of the drill bit diameter using a constant feed-rate $(75 \mathrm{~mm} / \mathrm{min})$ and drill speed $(600 \mathrm{rpm})$. For these conditions, results show that the smaller drill bit diameter leads to a decrease in the stress level in the foam material during the process.

\section{Keywords}

Polyurethane Foam, Drilling Process, Drill Diameter, Stress Level

\section{Introduction}

Several studies about drilling process in different materials have been published (Fernandes, Fonseca, Natal, Vaz, \& Dias, 2015).

Shaping operations through which excess material is removed could be categorized in different processes types: conventional machining (turning, drilling, milling or other operations), abrasive processes (grinding or other) and nontraditional processes (mechanical energy, electrochemical, thermal and chemical machining).

Drilling is one of the most complex machining process, due the combination of cutting and extrusion of material. Conventional machining in drilling process of different materials use a controlled drilling parameters. In case of human bone surgeries, the surgeon controls manually the drilling parameters, such as the feed-rate due the imposed load control by hand (Fernandes, Fonseca, \& Natal, 2017), (Fernandes, Fonseca, \& Natal, 2015). The orthopaedic surgery, neurosurgery, bone implant and repair operations are a few examples that involve these procedures, (Li, Abdel-Wahab, Demirci \& Silberschmidt, 2014). Several works have been published in the biomechanical area using experimental, numerical and analytical procedures. The main objective is to study the influence of different parameters in guarantee of the health and quality of human people. Valeeprakhon \& Eua-Anant, 2015, published one work focused on experimental results to count red blood cell using a new algorithm based on the displacement ratio criteria. Goswami et al., 2016 used a numerical simulation based on finite volume method to carried out on physiological pulsatile flow through a rigid arterial wall with the objective to study the atherosclerosis, as a cardiovascular disease. 
In this work two different methodologies for comparison were used to simulate the drilling process in solid rigid polyurethane foam materials. Different cutting parameters were used, namely three different drill diameters, with a constant feed-rate and a constant drill speed to improve the drilling process. The principal objectives of the study were as follows.

- To study the effect of the use of different drill bit diameter in the drilling of typical polyurethane foam materials with similar properties to the human bone (from Sawbones, Pacific Research Laboratories, Inc., Vashon. WA, USA).

- To obtain the level of stress in different material positions through a numerical model, using a three-dimensional dynamic finite element, calibrated with an experimental model using strain gauges.

All obtained conclusions in this work are important to increase the knowledge in bone drilling process, as a special topic, in all researches from our investigations (Lopes, Fernandes, Ribeiro \& Fonseca, 2017), (Fernandes, Fonseca \& Jorge, 2016), (Fernandes, Fonseca, \& Natal, 2016), (Fernandes, Natal, Fonseca, Ribeiro, \& Azevedo, 2017).

\section{Experimental Model}

Several linear strain gauges (1-LY18-6/120, $120 \Omega \pm 0.35 \%$ from HBM) were installed on the surface of the solid rigid polyurethane foam material to measure the level of strains during the drilling. The acquisition data system allowed to read the strains on different material positions along the time, for each used helicoidally and conventional drill diameter $(4,5$ or $6 \mathrm{~mm})$ during the machining process, always using a constant feed-rate $(75 \mathrm{~mm} / \mathrm{min})$, a constant drill speed (600rpm) and perforations with $30 \mathrm{~mm}$ of depth.

All experimental methodology was performed in Mechanical Laboratory at Polytechnic Institute of Bragança using a computer numerically controlled machine system, figure 1. In all measures, the same distance between the edge of the drilled hole and the middle of the strain gauge $(3,5 \mathrm{~mm})$ were considered.

During the tests, the solid rigid polyurethane foam material was at room temperature and remains equal at the distance where the strain gauges were installed (Fernandes, Fonseca, \& Natal, 2017). 

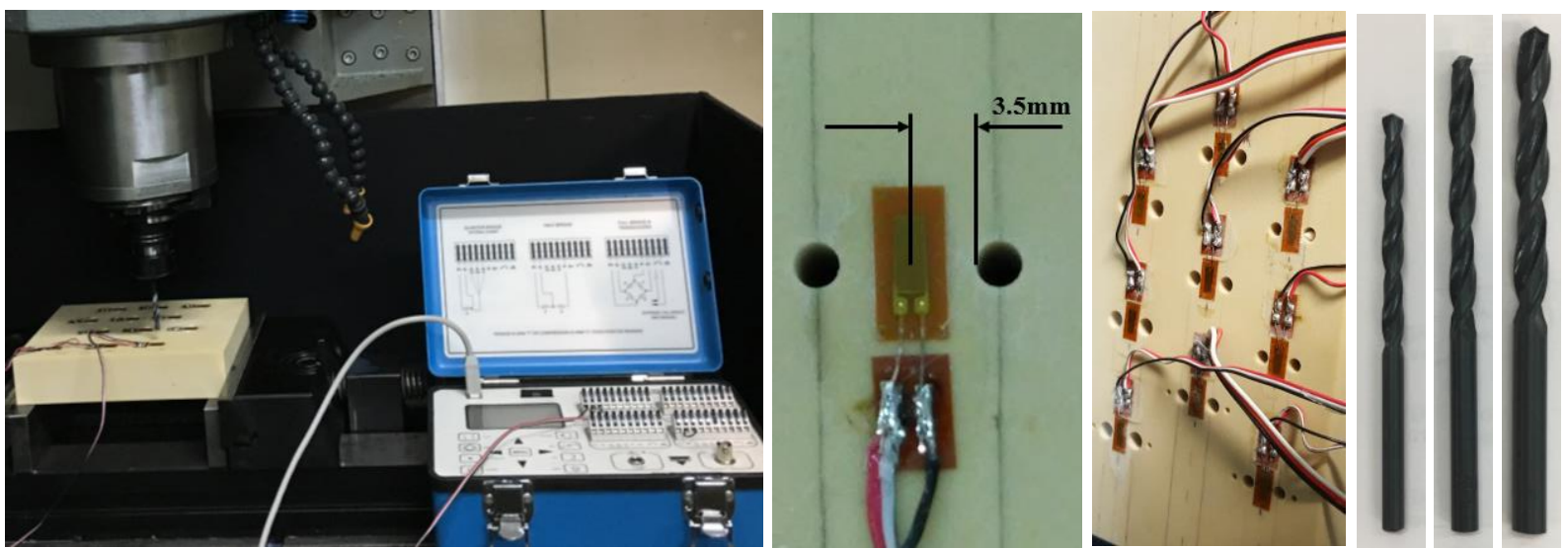

Figure 1: Experimental setup used for strain acquisition

\subsection{Experimental Results}

For all measured strain values, during the drilling process and with different drill tools, it was possible to identify the effect in the average of the stress level at the end of $30 \mathrm{~mm}$ depth perforation. The obtained experimental results are presented in figure 2.

An order 2 polynomial trendline illustrate the relationship between the drill bit diameter and the maximum stress obtained in the polyurethane foam material. It is notice that the Rsquared value is 1 , which is a good fit of the line to the data, and makes possible to determine the value of the stress level for any diameter drill bit in the observation range.

The results show that the smaller drill bit diameter at constant feed-rate $(75 \mathrm{~mm} / \mathrm{min})$ and drill speed (600rpm) leads to a decrease in the stresses generation in solid rigid polyurethane foam materials during drilling. 


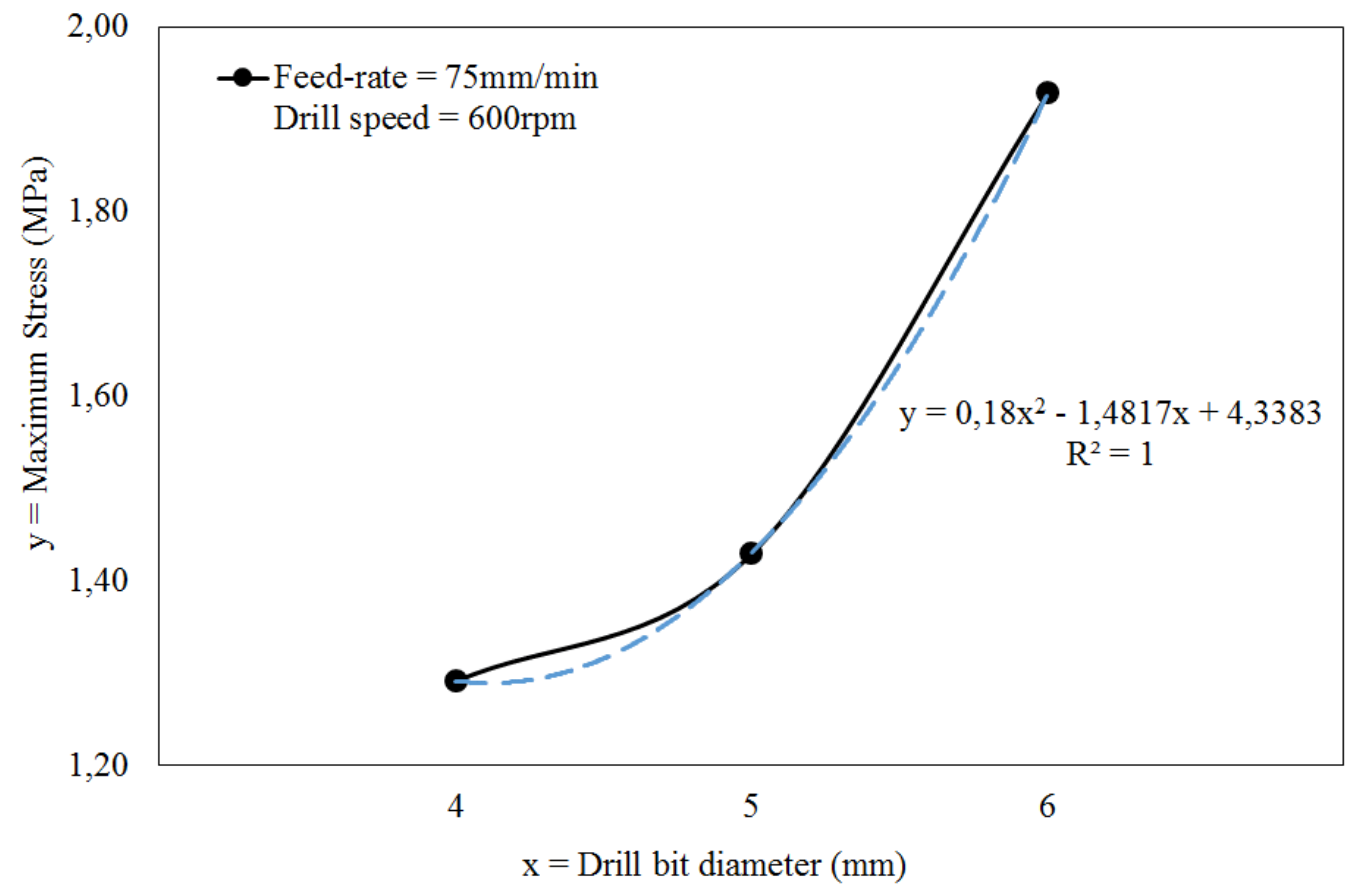

Figure 2: Experimental results for maximum stress at $30 \mathrm{~mm}$ of depth, function of drill bit

\section{Dynamic Numerical Model}

An explicit dynamic numerical model was developed using ANSYS program, most helpful in solving high deformation time dependent problem. This program is a nonlinear transient dynamic finite element program with both explicit and implicit solvers. Explicit scheme is a function of time, where the velocity and acceleration as well as the mass and damping need to be considered in this scheme. Central difference time integration is used to calculate field variables at respective nodal points, particularly suited for nonlinear problems. The equation of motion is evaluated at the previous time step and works in time step increments, where the displacements are calculated as the time proceeds. Gradually as time would progresses the deformation also would change.

The proposed numerical model intents to simulate the drilling process and to evaluate the mechanical stress distribution in polyurethane foam material.

The numerical model consists of a drill bit (with $4 \mathrm{~mm}, 5 \mathrm{~mm}$ and $6 \mathrm{~mm}$ of diameter, point angle of $118^{\circ}$ and helix angle of $30^{\circ}$ ) and a half of the representative polyurethane foam piece (4mm in depth), as represented in figure 3. 
The chosen finite element type was the 3D Solid 164, which consists of 8 nodes with three degrees of freedom in translation at each node.

A discretized mesh was used, according a length of the finite element equal to $0,5 \mathrm{~mm}$ for the drill bit and for the hole work piece, and a more spaced mesh with an element equal to $1 \mathrm{~mm}$ in the remain foam material.

All boundary conditions will be considered due the dynamics characteristics involved in drilling process. The polyurethane foam piece was fixed on the bottom, while the drill bit rotate and moves about its own longitudinal axis with a drill speed (600rpm) and a feed-rate $(75 \mathrm{~mm} / \mathrm{min})$ vertically downwards into the polyurethane foam.

Drill bit $4 \mathrm{~mm}$

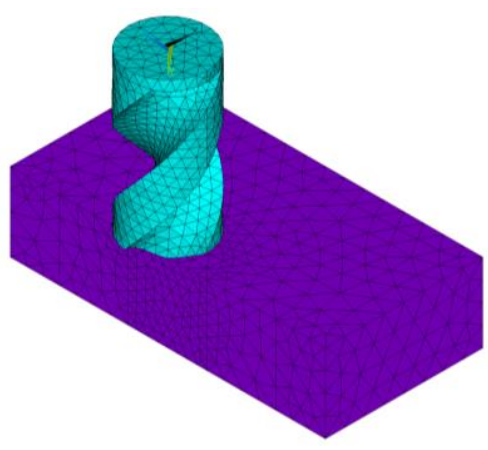

Drill bit $5 \mathrm{~mm}$

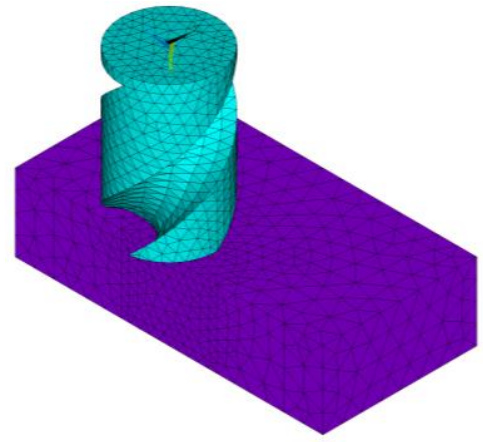

Drill bit $6 \mathrm{~mm}$

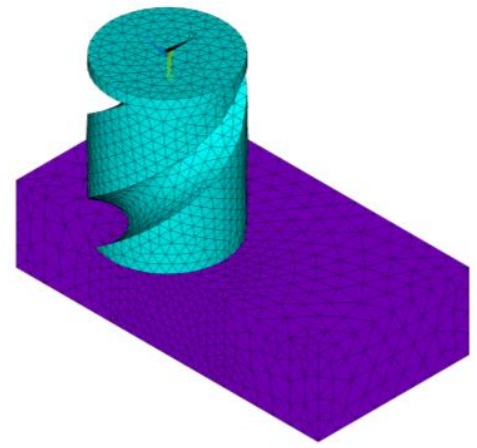

Figure 3: Numerical model for stress analysis

Numerical model of drilling process was formed evaluating contact between interacting bodies (polyurethane foam, as a deformable body and drill bit, as a rigid body).

In contact interaction was formulated using the algorithm proposed from the program *CONTACT_ERODING_SURFACE_TO_SURFACE, to define element deletion during the process. Contact surface is updated as elements on free surface are deleted according to material failure criteria, in this work considered as the Failure Strain equal to 0,05. Also, time step size is automatically adjusted to satisfy the contact between different bodies and the program checks all elements when calculating the required time step.

In explicit analysis, the time step is affected by element size and material sound speed. For stability reasons, a scale factor $(0,9)$ is used to decrease the time step. In all simulations the time step used was equal to $1.63154 \times 10^{-7} \mathrm{~s}$. 
To define the material model of the solid rigid polyurethane foam should be taken in consideration the strain-rate with dependency of the material plastic curve. Strain rate is accounted for using the Cowper-Symonds model which scales the yield stress by the strain rate dependent factor as shown in equation 1, (Fernandes, Fonseca, \& Natal, 2015), (Fernandes, Fonseca, \& Natal, 2017). This material model is an elastic-plastic with strain rate dependency and failure, which includes isotropic and kinematic hardening plasticity. In equation 1, isotropic and kinematic contributions may be varied by adjusting the hardening parameter $\beta$ between 0 (kinematic hardening only) and 1 (isotropic hardening only).

$$
\sigma_{y}=\left[1+\left(\frac{\dot{\varepsilon}}{C}\right)^{\frac{1}{p}}\right]\left(\sigma_{0}+\beta E_{p} \varepsilon_{p}^{e f f}\right)
$$

where $\sigma_{y}$ is the yield stress, $\sigma_{0}$ is the initial yield stress, $\dot{\varepsilon}$ is the strain rate, $\beta$ is the hardening parameter, $C$ and $P$ are the Cowper-Symonds strain rate parameters, $\varepsilon_{p}^{e f f}$ the effective plastic strain, and $E_{p}$ is the plastic hardening modulus which is dependent of the $E$ Young's Modulus and the $E_{\text {tan }}$ Tangent Modulus given by equation 2.

$$
E_{p}=\frac{E_{\text {tan }} E}{E-E_{\text {tan }}}
$$

In the numerical model, the Cowper-Symonds law is applied through the *MAT_PLASTIC_KINEMATIC (*MAT type 3) from the material program library.

The drill bit was modelled as a rigid body in order to reduce the computing time and resources, with high stiffness when compared with the solid rigid polyurethane foam material. The mechanical properties used in all numerical models are summarized in table 3.1, (Fernandes, Fonseca, \& Natal, 2015), (Fernandes, Fonseca, \& Natal, 2017).

Table 1: Material properties and Cowper-Symonds parameters

\begin{tabular}{|l|l|c|}
\hline \multicolumn{1}{|c|}{ Properties } & Polyurethane foam material & Drill bit \\
\hline Density $\left(\mathrm{kg} / \mathrm{m}^{3}\right)$ & 800 & 7850 \\
\hline
\end{tabular}




\begin{tabular}{|l|l|l|}
\hline Young's Modulus $(\mathrm{GPa})$ & 0,987 & 200 \\
\hline Poisson's ratio & 0,3 & 0,3 \\
\hline Initial Yield Stress $(\mathrm{MPa})$ & 22,59 & \\
\hline Tangent Modulus $(\mathrm{MPa})$ & 0,91 & \\
\hline Hardening Parameter & 0,1 & \\
\hline Cowper-Symonds parameter C & 2,5 & \\
\hline Cowper-Symonds parameter P & 7 & \\
\hline Failure Strain & 0,05 & \\
\hline
\end{tabular}

\subsection{Numerical Results}

Different numerical simulations were performed with the same drilling parameters used in experimental tests. Figure 4 shows the von-Mises stress distribution, chosen for a time instant equal to $3,25 \mathrm{~s}$ of drilling. The time equal to $3,5 \mathrm{~s}$ is the complete time to depth the polyurethane foam $(4 \mathrm{~mm})$ when a fee-rate equal to $75 \mathrm{~mm} / \mathrm{min}$ is used.

Drill bit $4 \mathrm{~mm}$

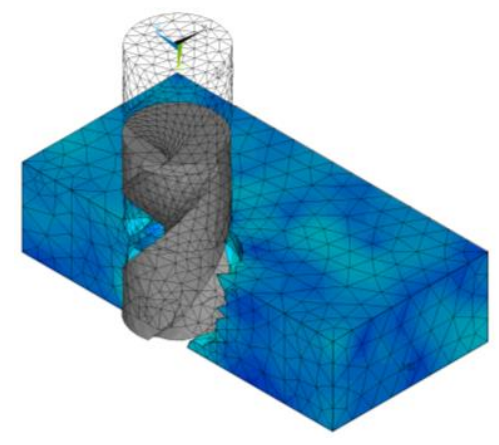

Drill bit $5 \mathrm{~mm}$

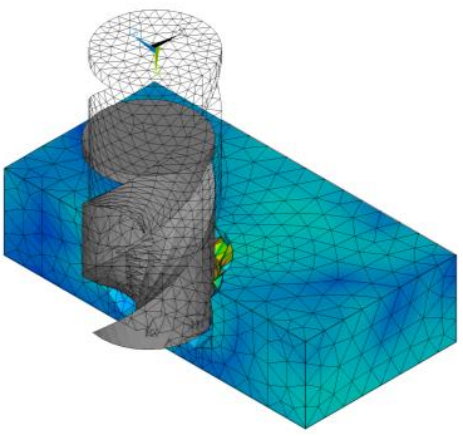

Drill bit $6 \mathrm{~mm}$

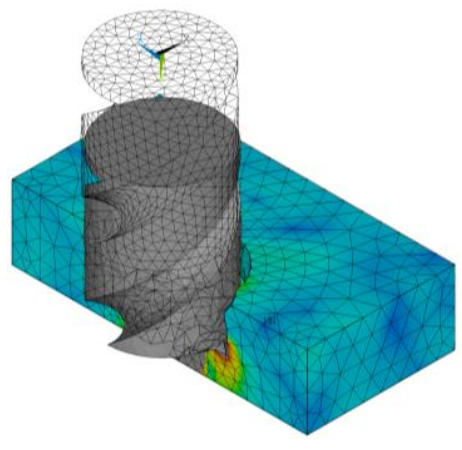

3.88911

Figure 4: Results for obtained von-Mises stresses [MPa] at time $=3,25$, function of drill bit

The numerical results show that the stress level in the material tend to increase with drill bit perforation. For the same time instant, represented in figure 4, the stress level increase with the increased drill bit diameter.

\section{Comparison of Results}


In order to allow a better comparison between the results for all drilling processes using different drill bit diameters, an average values of the normal stress at direction $\mathrm{zz}$ from numerical model and an average values from the strain gauges at $4 \mathrm{~mm}$ of drilling depth and same location, are presented in figure 5.

The experimentally measured stress level was compared to the predicted numerical value, with $7,7 \%$ deviation from the respective test results, as an average. However, the numerical model can be used as a validated drilling model, according the obtained deviation value, and due the good agreement between all results.

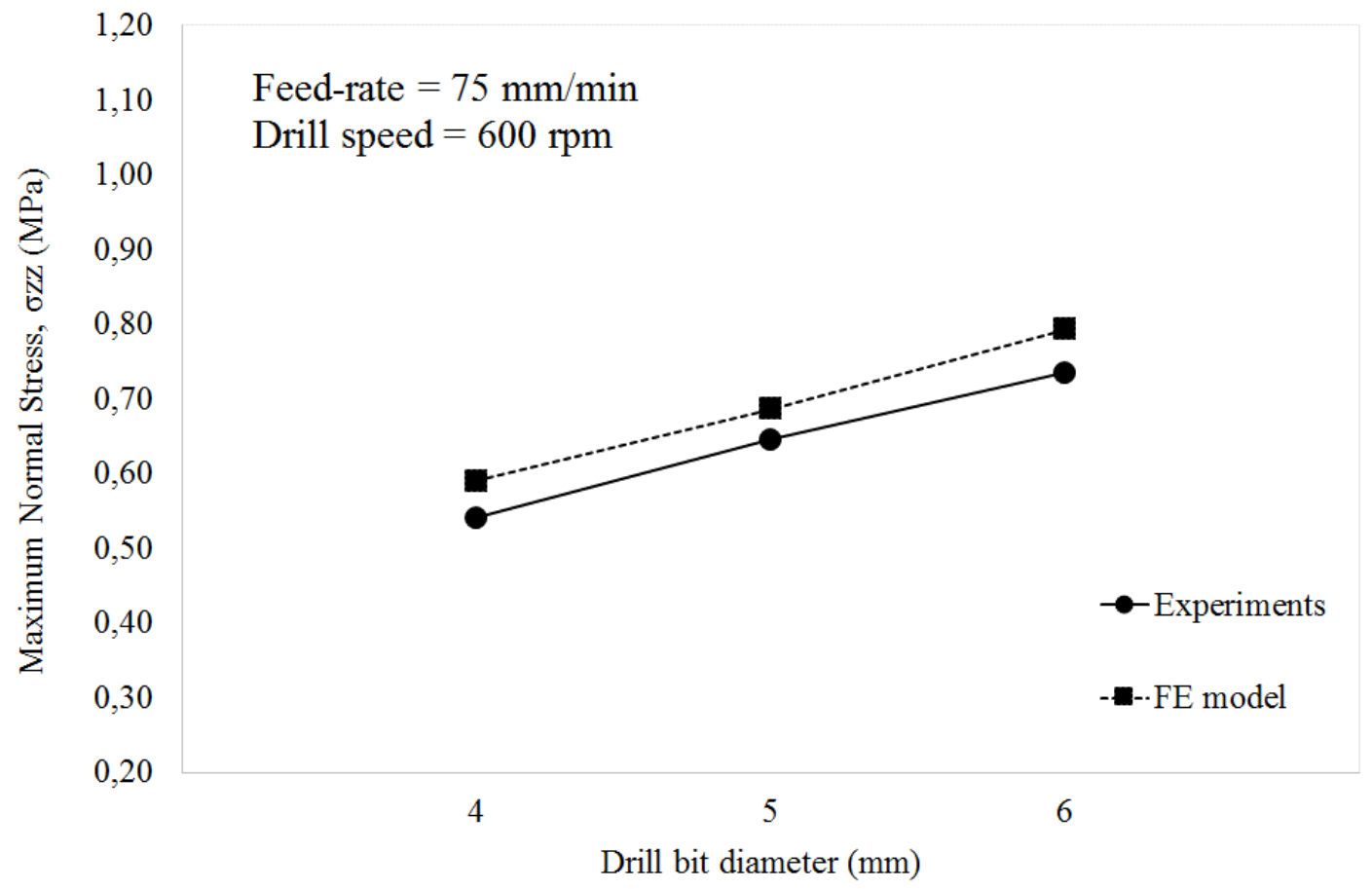

Figure 5: Results comparison for obtained stress at $4 \mathrm{~mm}$ of drilling depth, function of drill bit

According to numerical results, presented in figure 5 it is seen, that calculated average value of the maximum normal stress agree with the experimental values obtained from the strain gauges. Both results in figure 5 show that the increase in drill bit diameter leads to increase in stress level in polyurethane foam material.

\section{Conclusions}


This work proposes two different methodologies (experimental and numerical) for drilling processes in in polyurethane foam materials. Results of the conducted methodologies, using a constant drill speed and feed-rate, indicate that the use of an increased diameter in drill bit geometry produces high stress level on the material. The finite element model was calibrated with experimental results and enables the determination of drilling processes. The use of validated modeling tools could help in the analysis and definition of the used parameters in this process.

The mentioned approach shown very good potential of predicting the mechanical damage due the calculated stress level in the material submitted to drilling processes. The approach will simplify the complexity of the model in investigations about this subject and will facilitate professionals to produce perforations in some materials, as bone, due the combination of the used drilling parameters. However, the drill speed and the diameter of the drill bit could also affect the temperature distribution in materials. In present study a limitation was considered in the numerical model, considering only the mechanical effect and vanish the thermal effect produced by the tool.

Other researches have been developed by our investigations, where the temperature effect will be add to the numerical dynamic model to predicts this occurrence. In present study the solid rigid polyurethane foam material was at room temperature and remains equal at the distance where the strain gauges were installed for numerical model calibrating, in order to control the research limitation in the numerical simulation. For better performance of the drilling procedures, it is essential to understand the mechanical behavior of bones that leads to their failures and consequently to improve the cutting conditions. For this reason, future research using ex-vivo and cadaveric bone materials should be used to test and obtain more results to correlate with the present study.

\section{Acknowledgments}

This research was supported by the Portuguese Foundation of Science and Technology under the research project UID/EMS/50022/2013. The first author acknowledges the funding of Project NORTE-01-0145-FEDER-000022-SciTech-Science and Technology for Competitive and Sustainable Industries, cofinanced by Programa Operacional Regional do Norte (NORTE2020), through Fundo Europeu de Desenvolvimento Regional (FEDER). 


\section{References}

Lopes, A. C., Fernandes, M. G. A., Ribeiro, J. E., \& Fonseca, E. M. M. (2017). Determination of optimal parameters in drilling composite materials to minimize the machining temperature using the Taguchi method. Biodental 2016, Natal Jorge et al (Eds), by CRC Press, ISBN 9781138057371 - CAT\# K33277.

Goswami, P. et al. (2016). Analysis of wall shear parameters of physiological pulsatile flow through mild and severe arterial stenosis and correlation to atherosclerosis. MATTER: International Journal of Science and Technology, 2(3), 40-54.

Fernandes, M., Fonseca, E., Natal, R., Vaz, M. \& Dias, M. I. (2015). Composite Materials and Bovine Cortical Bone Drilling: Thermal Experimental Analysis. 6th International Conference on Mechanics and Materials in Design, J.F. Silva Gomes et Shaker A. Meguid (Eds.), FEUP-INEGI, ISBN: 978-989-989-98832-3-9, 1817-1824.

Fernandes, M. G., Fonseca, E. M., \& Natal, R. N. (2017). Thermo-mechanical stresses distribution on bone drilling: numerical and experimental procedures. Proc IMechE Part L: Journal of Materials: Design and Applications, https://doi.org/10.1177/1464420716689337

Fernandes, M. G., Fonseca, E. M., \& Natal, R. N. (2015). Three-dimensional dynamic finite element and experimental models for drilling processes. Proc IMechE Part L: Journal of Materials: Design and Applications, 1-9. https://doi.org/10.1177/1464420715609363

Fernandes, M. G., Fonseca, E. M. M., \& Jorge, R. N. (2016). Influence of bone drilling parameters on the thermal stress distribution. Proceedings of the 5th International Conference on Integrity-Reliability-Failure, J.F.Silva Gomes and S.A. Meguid (Eds.), Publ. INEGI/FEUP, ISBN: 978-989-98832-5-3, 517-528.

Fernandes, M. G. A., Fonseca, E. M. M., \& Natal, R. J. (2016). Thermal Analysis during bone drilling using rigid polyurethane foams: numerical and experimental methodologies. Journal of the Brazilian Society of Mechanical Sciences and Engineering, 38(7), 18551863. https://doi.org/10.1007/s40430-016-0560-4

Fernandes, M. G., Natal, R., Fonseca, E. M., Ribeiro, J. E. P. C., \& Azevedo, L. (2017). Effect of drill speed on bone damage during drilling. Biodental 2016, Natal Jorge et al (Eds), by CRC Press, ISBN 9781138057371 - CAT\# K33277. 
Valeeprakhon, T., \& Eua-Anant, N. (2015). Segmentation of connected red blood cells based on distance per displacement ratio maximization criterion. MATTER: International Journal of Science and Technology, 1(1), 132-143.

Li, S., Abdel-Wahab, A., Demirci, E., \& Silberschmidt, V. V. (2014). Penetration of cutting tool into cortical bone: experimental and numerical investigation of anisotropic mechanical behaviour. Journal of Biomechanics, 47(5), 1117-1126. https://doi.org/10.1016/j.jbiomech.2013.12.019 